\title{
Epidemiology and (neo-)colonialism
}

Reflecting on the complex and important issues raised in the paper by Luis Aviles in this issue of the journal, ${ }^{1} \mathrm{I}$ would like to discuss an example of how a recent shift in the epidemiological approaches used by researchers at an international agency may both mirror the underlying assumptions and reinforce the practice of neocolonialism. As experienced by many low income countries today, "neocolonialism" refers to the replacement of colonial powers' direct political and military control with indirect economic control by multilateral international lending agencies, bilateral donors (often including the former colonisers), and private, corporate investors from affluent countries. Underlying this new order are the basic free market assumptions that aggregate economic growth is the ultimate measure of societal development, and that optimal growth can only be attained when market forces are unimpeded by policies designed to redistribute wealth.

What is the relevance of these political and economic issues to epidemiology? For centuries, strong links between health and socioeconomic status/position (SES) have been demonstrated across diverse settings and health measures. Given that evidence, and the widening disparities in wealth occurring in countries of all income levels, many have argued for routine reporting and analysis of health information disaggregated by markers of SES. ${ }^{2-6}$ This perspective supports ongoing monitoring of social inequalities in health (SIH) within countries, that is, health disparities between subnational population groups defined by social factors such as poverty/wealth. With the goal of providing data needed to guide policies to reduce such disparities, a 1995-98 World Health Organisation (WHO) initiative focused in part on developing capacity within lower income nations for assessing SIH. ${ }^{3}{ }^{7}$ However, in contrast with the SIH approach to monitoring, the latest World Health Report of the $\mathrm{WHO}^{8}$ compares the magnitude of what I will refer to as individuals' inequalities in health (IIH) within countries, an indicator measuring health disparities among individuals without regard for their social characteristics. The report's authors argued elsewhere ${ }^{9}$ that monitoring health disparities by comparing social groups selected a priori (that is, using $\mathrm{SIH}$ ) is inherently flawed ${ }^{9}$; a paper we wrote with two other epidemiologists refutes these charges. ${ }^{10}$ Without repeating those arguments or our rebuttal, it suffices to note that since 1998, WHO resources for health monitoring have focused on measuring $\mathrm{IIH}$ and the earlier SIH focused WHO work has been discontinued. I perceive the shift to IIH and away from SIH as a primary epidemiological approach to assessing health inequalities to be associated with neocolonialism in that (1) using IIH is inherently more compatible conceptually with basic assumptions underlying neocolonialism, and (2) in practical terms, information based on IIH is far less likely to challenge the prevailing conditions of neocolonialism.

Neocolonialism operates on the assumptions that market forces should predominate everywhere, both between and within countries of all per capita income levels, and should not be regulated by governments to protect the disadvantaged. Lack of incentives for investment and productivityrather than historically unfair relationships between the rich and the poor-are viewed as the main obstacles to economic growth, which will automatically improve living standards for everyone. This view either assumes there is fair opportunity for everyone to compete in the marketplace, or does not perceive such fairness as a priority. Conceptually, the choice of $\mathrm{IIH}$ rather than SIH as an indicator for monitoring health inequalities is much more compatible with these assumptions. Using IIH as an indicator, one knows only the magnitude of health disparities between ungrouped individuals, without knowing any of the social characteristics with which the disparities are associated. IIH could, for example, be associated as strongly with differences in topography, climate, or the efficiency of newborn/infant health services as with disparities in wealth within a country. Indeed, IIH proponents have argued that policymakers should not necessarily be more concerned about ill health in socially disadvantaged persons. ${ }^{9}$

In contrast, choosing to monitor SIH implicitly acknowledges that some population groups are at an underlying disadvantage and assumes that policies should place a high priority on reducing health disparities between more and less advantaged social groups. Indeed, the express intent of monitoring SIH is to guide policies designed to reduce differences in social advantage and/or its health effects. Proponents of the use of SIH for monitoring health inequalities have argued that-while on a personal and clinical level one should be equally concerned about suffering regardless of whom is afflicted-public policies must preferentially protect those whose circumstances put them at an inherent disadvantage for attaining good health on their own. ${ }^{10}$

In addition, in practical terms, the move to use primarily IIH rather than SIH for monitoring health inequalities seems likely to reinforce prevailing neocolonialist conditions. Because the use of IIH as an indicator in place of SIH limits the extent to which low income countries can document widening disparities in health between different social groups within their national populations, it leaves policymakers and advocates without evidence that could suggest detrimental impacts of national and international policies on the health of socially disadvantaged groups. One might assume that IIH could perhaps be used as a proxy for SIH, but this clearly was not its proponents' intention ${ }^{9}$ and to our knowledge there has been no validation to support such an assumption. Furthermore, proponents of the IIH approach have argued, as justification for discontinuing prior SIH focused work at WHO, that cross national comparisons cannot be made using SIH. We disagree, and believe that the additional methodological work needed to permit broader comparisons using SIH would require relatively modest support that could (and should) be provided by WHO. Furthermore, we believe that replacing the earlier efforts to build lower income countries' capacity to monitor SIH with the more recent work focused on cross national comparisons using IIH has the serious practical consequence of reinforcing control of expertise and information in international organisations rather than developing monitoring capacity within countries themselves.

In the example discussed here, proponents of measuring IIH have called into question the scientific basis and importance of studying $\mathrm{SIH}$, and resources formerly devoted to studying social inequalities have been reallocated to work focused on individual inequalities. I believe this is unfortunate, and hope for a redirection of WHO efforts. We are hopeful in part because there is little or no support for the IIH approach - on conceptual or technical groundsamong others within and outside WHO. But we also are hopeful because of other WHO work-for which the proponents of IIH deserve considerable credit-that is helping to put issues of fair financing and health inequalities 
higher up on the agenda for evaluating the performance of national health systems. ${ }^{8}$ It should not be surprising that epidemiology, like all sciences, tends to mirror (in more or less subtle ways) the prevailing ideological perspectives of the society in which the scientists live and work. We cannot escape this tendency entirely, but we can strive to be more aware of the assumptions that underlie our analytical methods and to expose those assumptions to more rigorous scrutiny and open debate. This journal should be commended for providing this forum, particularly on such a controversial topic.

The author wishes to acknowledge the very helpful and extensive editorial assistance of Dr Susan Egerter, and also very helpful comments from Dr Catherine Cubbin.

University of California, San Francisco, USA
PAULA A BRAVEMAN
1 Avilés LA. Epidemiology as discourse: the politics of development institutions in the Epidemiological Profile of El Salvador. F Epidemiol Community Health 2001;55:164-71.

2 Braveman PA, Tarimo E. Avoidable social inequalities in health within countries: not only an issue for affluent nations. Soc Sci Med (in press).

3 Braveman P. Monitoring equity in health: a policy-oriented approach in low- and middle-income Countries. (WHO/CHS/HSS/98.1) Geneva: World Health Organization Department of Health Systems, 1998:92.

4 Gwatkin DR. Health inequalities and the health of the poor. Bull World Health Organ 2000;78:3-18.

5 Mackenbach, JP, Kunst AE. Measuring the magnitude of socio-economic inequalities in health: an overview of available measures illustrated with two examples from Europe. Soc Sci Med 1997;44:757-71.

6 Wagstaff A, Pci P, van Doorslaer E. On the measurement of inequalities in health. Soc Sci Med 1991;33:545-57.

7 World Health Organization/Braveman P. Equity in health and health care: a World Health Organization (WHO) initiative. Geneva: WHO, 996.

8 World Health Organization. World Health Report 2000. Geneva: WHO, 2000.

9 Murray C, Gakidou EE, Frenk J. Health inequalities and social group differences: what should we measure? Bull World Health Organ 1999;77: 537-43.

10 Braveman, P, Krieger, N, Lynch, J. Health inequalities and social inequalities in health. Bull World Health Organ 2000;78:232-4. 